\title{
МЕТОДИЧЕСКИЕ ПОДХОДЫ ДЛЯ ОЦЕНКИ ВТОРИЧНОГО ЗАГРЯЗНЕНИЯ ПИТЬЕВЫХ ВОД И ЕЕ АДЕКВАТНОЙ ДООЧИСТКИ
}

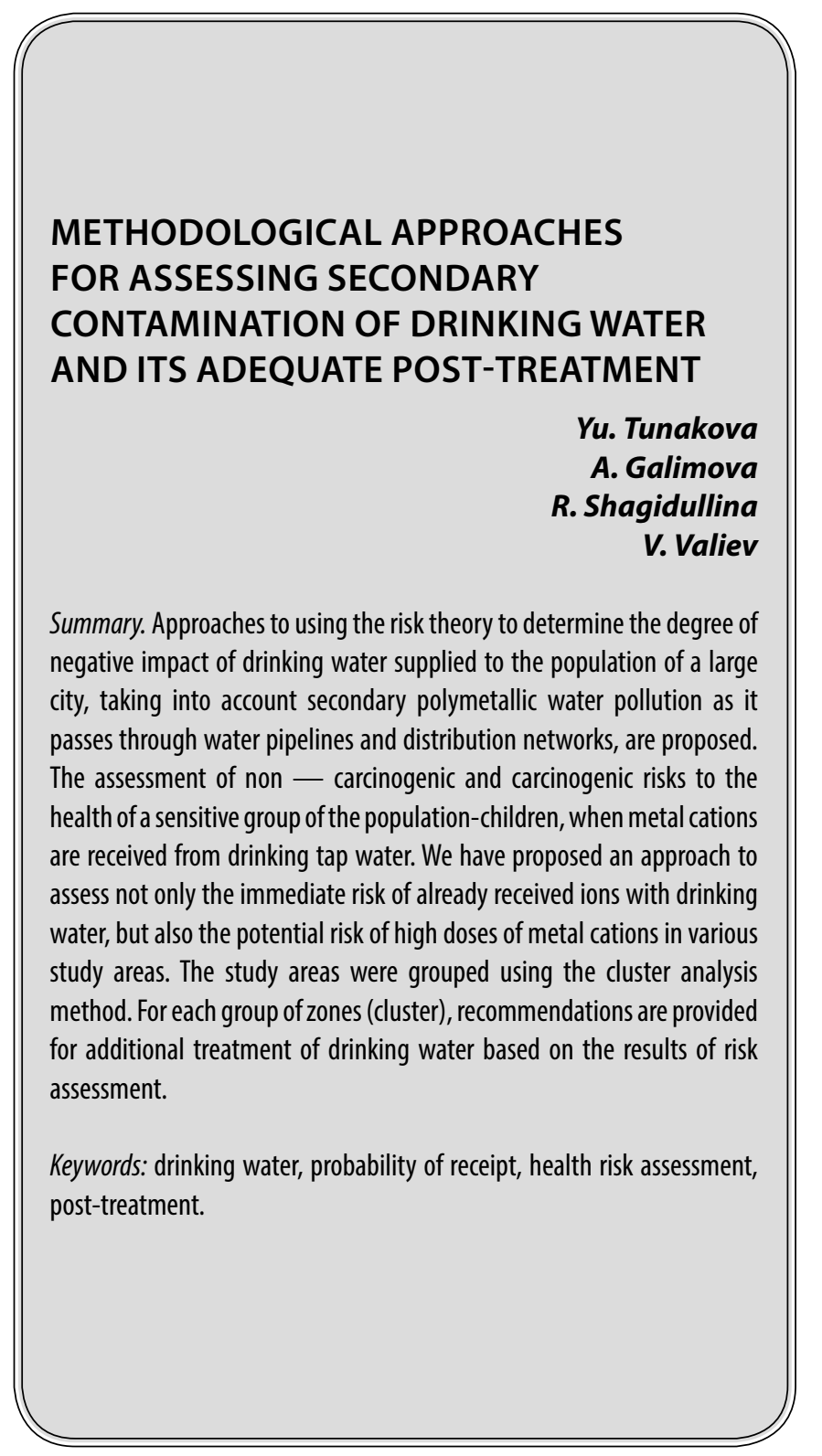

\section{Введение}

И спользование прикладных методов оценки риска обеспечивает адекватную количественную оценку воздействия загрязняющих веществ, особенно в динамичных экологических условиях городской среды, а также при комплексном и сочетанном воздействии целого спектра неблагоприятных факторов [1-6].
Тунакова Юлия Алексеевна

Д.х.н., профессор, Казанский национальный исследовательский технический университете им. А.Н. Туполева - КАИ juliaprof@mail.ru

Галимова Алина Раисовна

К.х.н., доцент, Казанский национальный исследовательский технический университете им. А. Н. Туполева - КАИ ARGalimova@kai.ru

Шагидуллина Раиса Абдулловна

Д.х.н., начальник управления обеспечения экологической безопасности и экологического мониторинга, Министерство экологии и природных ресурсов Республики Татарстана raisa.shagidullina@tatar.ru

Валиев Всеволод Сергеевич С.н.С., Институт проблем экологии и недропользования АН РТ (2. Казань) podrost@mail.ru

Аннотация. Предложены подходы по использованию теории риска для определения степени негативного воздействия питьевых вод, поступающих к населению крупного города, с учетом вторичного полиметаллического загрязнения вод по мере прохождения по водоводам и разводящим сетям. Проведена оценка неканцерогенного и канцерогенного рисков здоровью чувствительной группы населения - детей, при поступлении катионов металлов с питьевой водопроводной водой. Нами предложен подход для оценки не только непосредственного риска уже поступивших ионов с питьевой водой, но и потенциального риска поступления высоких доз катионов металлов в различных зонах исследования. Зоны исследования были сгруппированы методом кластерного анализа. Для каждой группы зон (кластера) представлены рекомендации о доочистке питьевых вод по результатам оценки риска.

Ключевые слова: питьевая вода, вероятность поступления, оценка риска здоровью, доочистка.

По определению Британского института стандартов риском называется вероятность частоты неблагоприятного события, представленная с учетом величины последствий этого события, в связи с чем риск, как особую категорию вероятностной оценки, можно использовать для установления границ приемлемости воздействия и целесообразности, а также эффективности мероприятий по устранению воздействия негативных факторов 
среды обитания и обеспечению безопасности в конкретных условиях [7-13].

Применяемые за рубежом подходы к оценке риска в целом схожи. На первом этапе проводится экологический мониторинг определенного участка территории на предмет содержания в выбранных средах (вода, почва, воздух) различных загрязняющих веществ. Затем измеренные концентрации сравниваются с пороговыми значениями, выбор которых зависит от целей оценки риска. В качестве скрининговых приоритетных веществ обычно исследуется ограниченный перечень токсикантов, в который входят и металлы [14-16].

Химические элементы, в том числе металлы, непрерывно циркулируют через организм человека, поступая в него преимущественно с пищей и водой, имеют высокие коэффициенты биологического накопления и значительное время удерживания в организме, что приводит к их накоплению в органах и тканях $[17,18]$.

Оценка риска поступления металлов с питьевой водой имеет особую значимость в виду активной ионной формы нахождения металлов [19-20].

Исследования, проводимые в нашей стране, показывают, что питьевая вода в процессе транспортировки по водопроводящим магистралям может в значительной степени загрязняться целым рядом химических элементов, особенно металлами. Коррозия труб и некачественные материалы, из которых изготавливают соединительные элементы, способны создать условия для значительного вторичного загрязнения воды [21].

\section{Цель работы}

Развитие подходов для оценки качества и требуемой степени очистки питьевых вод, поступающих к потребителям, на основе расчета риска здоровью представителей наиболее чувствительной к неблагоприятным воздействиям группы населения.

\section{Материалы и методы исследования}

На первом этапе исследования было изучено качество питьевой воды непосредственно в точках потребления (домах и квартирах) на территории города Казани в период с 2012 по 2018 гг. С этой целью пробы водопроводной воды отбирались в квартирах жителей, проживающих в разных участках города, соответствующих 11 зонам обслуживания детских поликлиник. Такое зонирование территории преследовало несколько целей. Во-первых, разделение территории урбоэкосистемы на участки обеспечивает градиент условий экспозиции. Во-вторых, позволит в последующем четко сопоставить места проживания, дозы токсичных металлов и условия их экспозиции с медицинскими анамнезами обследуемых. Наконец, разделение территории города по зонам призвано облегчить задачу доведения разработанных рекомендаций по доочистке питьевых вод до населения. Дети являются чувствительной группой населения, отражающей отклик на негативное воздействие факторов среды обитания. Интенсивный обмен веществ, неустойчивость эндокринной и иммунной систем обеспечивают высокую чувствительность детского организма к качеству среды обитания, в том числе к качеству потребляемой питьевой воды. При этом латентный период до проявления неблагоприятных эффектов у них значительно короче, чем у взрослых. К тому же дети в меньшей степени, чем взрослые, подвержены внутригородской миграции; они теснее привязаны к территории проживания. В рамках настоящего исследования в разных зонах были сформированы группы детей 3-6 лет со сравнительно однородным водопотреблением, режимом и образом жизни $[22,23]$.

В данной работе качество питьевой воды определялось по содержанию в ней катионов металлов $\left(\mathrm{Pb}^{2+}\right.$, $\mathrm{Cu}^{2+}, \mathrm{Zn}^{2+}, \mathrm{Cr}$ (суммарно), $\mathrm{Sr}^{2+}, \mathrm{Fe}$ (суммарно)), поступающих от разных источников водоснабжения и по мере прохождения по водоразводящим путям. Определение концентраций катионов металлов в воде проводилось методом атомной абсорбции на атомно-абсорбционном спектрофотометре AAnalyst 400 (Perkin Elmer). Статистическая обработка вариационных рядов проводилась с помощью программного комплекса «STATISTICAv.6.0» с использованием методов вариационной статистики, дисперсионного и кластерного анализов.

Оценка неканцерогенного и канцерогенного риска здоровью детского населения проводилась на основании методик, изложенных в руководстве Р 2.1.10.1920041', применяющем величины референтных доз, которые являются индивидуальной характеристикой каждого вещества (пороговая модель расчета). Также использовалась беспороговая модель оценки риска по стандартной методической рекомендации МР 2.1.4.0032-11². Оценка канцерогенного риска потребления питьевой воды с полиметаллическим вторичным загрязнением проводилась по регламентированной методике (Р 2.1.10.192004). При оценке канцерогенного риска применялась

Р 2.1.10.1920-04. Руководство по оценке риска для здоровья населения при воздействии химических веществ, загрязняющих окружающую среду [Электронный ресурс] // КОДЕКС: электронный фонд правовой и нормативнотехнической документации._- URL: http://docs.cntd.ru/document/1200037399 (дата обращения: 15.01.2018).

2 МУ 2.3.7.2519-09. Определение экспозиции и оценка риска воздействия химических контаминантов пищевых продуктов на население [Электронный pecypc]._-URL: https://rospotrebnadzor.ru/documents/details.php? ELEMENT_ ID=4799 (дата обращения: 15.01.2018). 


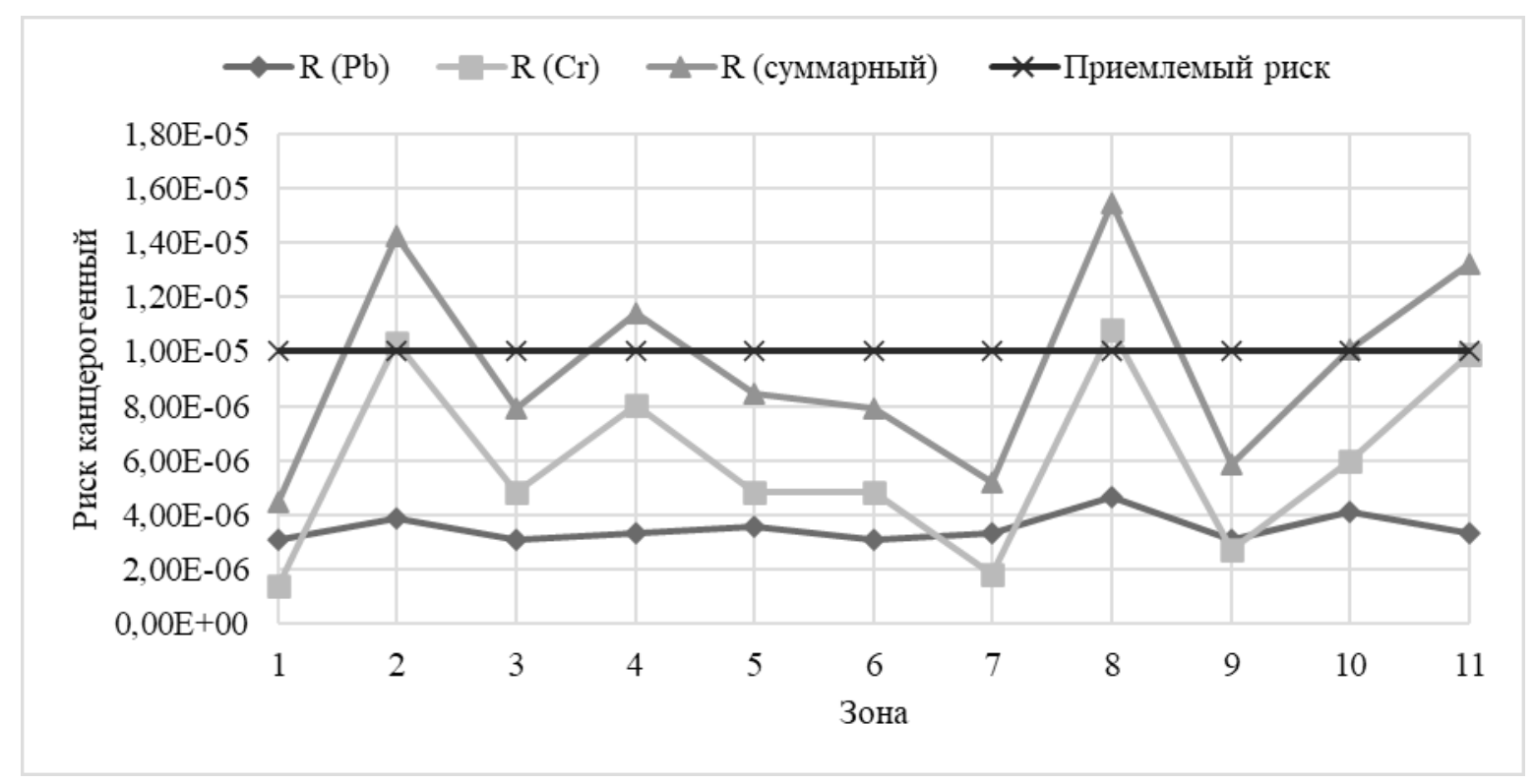

Рис. 1. Уровни канцерогенного риска по зонам исследования

беспороговая модель, при которой полученная величина риска показывала вероятность развития онкологических заболеваний при заданных уровнях дозовых нагрузок (индивидуальный риск).

\section{Результаты и обсужления}

Статистический анализ результатов исследования показал широкий размах концентраций катионов исследуемых металлов в водопроводной воде, отобранной в разных зонах исследования, что обусловлено как разными источниками водоснабжения (поверхностные и подземные), так и различной степенью изношенности и коррозии конкретных водопроводящих магистралей.

При анализе условий и факторов экспозиции было отмечено, что рассчитанные дозы металлов, характерные для хронического перорального поступления с питьевой водой, не превышают референтные уровни (RFD), рекомендованные для детского населения. Анализ аддитивного однонаправленного действия исследуемых ионов, содержащихся в водопроводной воде, на органы/системы-мишени показал, что индексы опасности хронического воздействия не превышают допустимый уровень для детского населения. Определенный нами неканцерогенный риск также не превышает приемлемых значений ни в одной зоне.

Далее нами был проведен анализ канцерогенного риска здоровью детского населения. Среди исследуемых катионов металлов канцерогенным эффектом обладают ионы свинца и хрома.
Полученные значения канцерогенного риска от поступления канцерогенных металлов с питьевой водой для детей возраста до 6 лет по стандартным значениям факторов экспозиции представлены на рисунке. Согласно рекомендациям ВО3, приемлемым значением канцерогенного риска для питьевых вод считается величина $1 \cdot 10^{-5}$.

Таким образом, результаты расчетов показали, что суммарный канцерогенный риск здоровью от потребления питьевой воды детьми до 6 летнего возраста, рассчитанный по стандартным значениям факторов экспозиции, в зонах 1, 3, 5, 6, 7 и 9 не превышает приемлемых значений канцерогенного риска для питьевой воды, рекомендованных ВОЗ. В зонах 4 и 10 наблюдается превышение приемлемых значений риска на 1-15\%. Максимальное превышение значений наблюдается в зонах 2, 8 и 11, в которых приемлемое значение превышено на $32-55 \%$.

Предлагаемый нами подход предполагает не только расчет непосредственного риска здоровью человека высоких концентраций в воде хрома и свинца, но также и оценку вероятности появления таких концентраций. Предлагаемая методика рассчитывает вероятность превышения в воде концентраций с учетом принятого зонирования территории. Собственно расчет вероятности базируется на положениях теоремы Байеса, согласно которым была оценена апостериорная вероятность превышения условно безопасной дозы металлов, рассчитываемой как верхний квартиль ранжированного ряда фактических данных, полученных для разных зон исследования. Такая вероятность носит относительный 
Таблица 1. Средние значения выбранных индикаторов ранжирования по кластерам

\begin{tabular}{|l|l|l|l|} 
& $\begin{array}{l}\text { Кластер № 1 } \\
\text { (зоны№ 1, № 3, № 5, № 6, № 7 и № 9) }\end{array}$ & $\begin{array}{l}\text { Кластер № 2 } \\
\text { (зоны № 2, № 8 и № 10) }\end{array}$ & $\begin{array}{l}\text { Кластер № 3 } \\
\text { (зоны№ 4 и № 11) }\end{array}$ \\
\hline $\mathrm{HQ}(\mathrm{Sr})$ & 0,0207 & 0,0344 & 0,0162 \\
\hline $\mathrm{HQ}(\mathrm{Cu})$ & 0,0087 & 0,0065 & 0,0084 \\
\hline $\mathrm{HQ}(\mathrm{Pb})$ & 0,5832 & 0,8310 & 0,6265 \\
\hline $\mathrm{HQ}(\mathrm{Zn})$ & 0,0049 & 0,0060 & 0,0061 \\
\hline $\mathrm{HQ}(\mathrm{Cr})$ & 0,0443 & 0,1577 & 0,1407 \\
\hline $\mathrm{HQ}(\mathrm{Fe})$ & 0,0214 & 0,0213 & 0,0200 \\
\hline $\mathrm{R}_{\text {кани }}(\mathrm{Pb})$ & 0,000005 & 0,000006 & 0,000005 \\
\hline $\mathrm{R}_{\text {кани }}(\mathrm{Cr})$ & 0,000005 & 0,000013 & 0,000013 \\
\hline $\mathrm{R}_{\sigma}(\mathrm{Sr})$ & 0,0433 & 0,1187 & 0,1920 \\
\hline $\mathrm{R}_{\sigma}(\mathrm{Cu})$ & 0,027 & 0,1627 & 0,1750 \\
\hline $\mathrm{R}_{\sigma}(\mathrm{Pb})$ & 0,0235 & 0,1840 & 0,1535 \\
\hline $\mathrm{R}_{\sigma}(\mathrm{Zn})$ & 0,0266 & 0,1363 & 0,2155 \\
\hline $\mathrm{R}_{\sigma}(\mathrm{Cr})$ & 0,0185 & 0,1576 & 0,2080 \\
\hline $\mathrm{R}_{\sigma}(\mathrm{Fe})$ & 0,0433 & 0,1116 & 0,2025 \\
\hline $\mathrm{R}_{\sigma}(\mathrm{Me})$ & 0,0275 & 0,1463 & 0,1725 \\
\hline & & & \\
\hline
\end{tabular}

HQ - коэффициент опасности, показывающий превышение среднесуточной дозы металлов, поступивших с питьевой водой при стандартных значениях экспозиции, безопасного уровня воздействия, то есть RFD.

$\mathrm{R}_{\text {кани }}$ - канцерогенный риск, описывающий вероятность развития онкологических заболеваний при заданных уровнях дозовых нагрузок (индивидуальный риск).

$\mathrm{R}_{\sigma}$ - вероятность поступления высоких доз металлов с питьевой водой, рассчитанная по теореме Байеса.

характер, определяясь как вероятность наблюдения факта превышения в конкретной зоне исследования при известных вероятностях наблюдения этого же события в других зонах, в том случае, если такое превышение отмечалось по крайней мере в одной из зон исследования.

Следует отметить, что событием, вероятность которого рассчитывается нашим методом, является превышение конкретно наблюдаемых значений концентраций металлов верхнего квартиля (охватывает 75\% всех значений ряда) ранжированного ряда из всех наблюдаемых значений оцениваемых доз. Факт превышения дозы фиксировался путем расчета кратностей превышения верхних квартилей, как отношение порога к конкретному значению концентрации, что позволило автоматизировать алгоритм, задавать при необходимости требуемую для определенных условий чувствительность, а также интегрировать события, полученные для разных металлов в общую оценку, рассматривая их в комплексе, как единое событие.

Согласно теореме Байеса вероятность события, определяемого нами как превышение дозы, которое произойдет в конкретных условиях экспозиции (такие условия выделены в виде зон исследования), определяется как отношение произведения доли неблагоприятных событий среди всех наблюдений, зафиксированных для конкретных условий, с долей числа наблюдений в этих условиях среди всех наблюдений во всех возможных условиях к сумме всех таких произведений, полученных для всех возможных условий. Иначе говоря, вероятность превышения дозы в оцениваемой зоне равна отношению произведения доли числа таких превышений в этой зоне с долей числа наблюдений в зоне относительно всех наблюдений к сумме всех подобных произведений полученных для всех зон исследования.

Относительные кратности превышения можно оценить путем их сопоставления с математическим ожиданием в ряду всех отмеченных кратностей. Такая относительная кратность является характеристикой вероятности события, при этом плотность распределения этих событий охватывается экспоненциальными функциями вида: $R=1-\exp \left(-\sum P\right)$, где $\sum P$ - совокупность вероятностей наблюдаемых кратностей превышения.

С целью ранжирования рекомендаций по снижению риска, методом кластеризации все выделенные зоны исследования были сведены в ряд групп. В качестве параметров при кластеризации использовались показатели рисков (канцерогенного и неканцерогенного), а также 
рассчитанные вероятности превышения поступающих с питьевой водой доз металлов. Вошедшие в разные кластеры зоны исследования средние по зонам значения различных рисков и вероятностей загрязнения питьевой воды представлены в таблице 1.

В кластер № 1 входят зоны № 1, № 3, № 5, № 6, № 7 и № 9. Перечисленные зоны имеют минимальные значения уровней канцерогенных и неканцерогенных рисков, а также наименьшие вероятности превышения верхнего квартиля доз поступающих с питьевой водой катионов металлов. Но при этом уровни канцерогенного риска, возникающего в результате наличия ионов свинца и хрома в питьевой воде, превышают приемлемый уровень риска, рекомендованный ВОЗ. Соответственно, в указанных зонах необходимо проводить доочистку водопроводных вод перед употреблением бытовыми фильтрами, имеющимися на потребительском рынке.

Кластер № 2 содержит зоны № 2, № 8 и № 10, в которых вероятность превышения верхнего квартиля доз ионов металлов в питьевой воде имеет средние значения, а неканцерогенный риск высокие уровни. Однако своих максимумов в данном кластере достигают уровни канцерогенного риска, что требует для указанных зон избирательную доочистку водопроводной воды перед употреблением от ионов свинца и хрома с тщательным подбором фильтросистем по полученным результатам оценки.

Зоны кластера № 3 (№ 4 и № 11) характеризуются средними и выше среднего значениями показателей всех индикаторов ранжирования. Поэтому в указанных зонах требуется использование высокоэффективных устройств доочистки водопроводных вод с их тщательным подбором в каждом конкретном случае.

\section{Зак^ючение}

Таким образом, оценка риска позволяет разрабатывать более гибкие и адекватные адресные рекомендации по обеспечению химической безопасности населения при употреблении питьевой воды неудовлетворительного качества. Результаты оценки риска здоровью детского населения можно использовать для определения необходимой степени доочистки питьевых вод и обоснованного выбора специальных бытовых систем доочистки воды непосредственно в конечной точке потребления. Для зон с превышением приемлемого значения канцерогенного риска рекомендуется применение эффективных методов доочистки питьевых вод от ионов, обладающих канцерогенным потенциалом.

\section{ЛИТЕРАТУРА}

1. Абдулмуталимова Т. 0., Ревич Б. А. Оценка канцерогенного риска здоровью населения, обусловленного высоким содержанием мышьяка в питьевой артезианской воде Северного Дагестана // Гигиена и санитария. — 2017.— № 8. - C. 743-746.

2. Авалиани С. Л., Безпалько Л. Е., Бобкова Т. Е., Мишина А. Л. Перспективные направления развития методологии анализа риска в России// Гигиена и санитария.-2013.— № 1.-С. 33-35.

3. Боев В.М., Кряжева Е. А., Бегун Д. Н., БорщукЕ.Л., Кряжев Д. А. Гигиеническая оценка риска здоровью населения при комбинированном пероральном поступлении тяжелых металлов // Анализ риска здоровью. — 2019.— № 2.—C. 35-43.

4. Новиков С. М., Фокин М. В., Унгуряну Т. Н. Актуальные вопросы методологии и развития доказательной оценки риска здоровью населения при воздействии химических веществ // Гигиена и санитария.—2016.—№ 8.—C. 711-716.

5. Рахманин Ю. А., Новиков С. М., Иванов С. И. Современные научные проблемы совершенствования оценки риска здоровью населения // Гигиена и санитария.— 2005.—№ 2.-С. 7-10.

6. Фридман К.Б., Новикова Ю. А., Белкин А.С. Оценка риска для здоровья в целях гигиенической характеристики систем водоснабжения // Гигиена и санитария.— 2017.— № 7.—C. 686-689.

7. Owens S., Rayner T. When Knowledge Matters: The Role and Influence of the Royal Commission on Environmental Pollution // Journal of Environmental Policy \& Planning. — 1999.—V.1, № 7.—P. 24.

8. Miller F.J., Schlosser P. M., Janszen D. B. Haber's rule: A special case in a family of curves relating concentration and duration of exposure to a fixed level of response for a given endpoint // Toxicology. - 2000. - 149(1). - P.21-34.

9. Renwick A.G., Lazarus N. R. Human Variability and Noncancer Risk Assessment: An Analysis of the Default Uncertainty Factor // Regulatory Toxicology and Pharmacology. - 1998. - 27(1).-P. 3-20.

10. Зайцева Н.В., Сбоев А.С., Клейн С. В., Вековшинина С. А. Качество питьевой воды: факторы риска для здоровья населения и эффективность контрольно-надзорной деятельности Роспотребнадзора // Анализ риска здоровью. - 2019. — № 2.- C. 44-55.

11. Нефедова Е.Д., Хямяляйнен М. М., Ковжаровская И. Б., Шевчик Г. В. Риск-ориентированный подход к организации контроля качества питьевой воды // Водоснабжение и санитарная техника.— 2018.— № 3.- С. 5-9.

12. Онищенко Г. Г. Оценка и управление рисками для здоровья как эффективный инструмент решения задач обеспечения санитарно-эпидемиологического благополучия населения Российской Федерации // Анализ риска здоровью.—2013.— № 1.—C. 4-14. 
13. Тулакин А.В., Плитман С. И., Амплеева Г. П., Пивнева 0. С. Риск-ориентированный надзор как основа обеспечения безопасности питьевой воды: Проблемы и возможности // Научно-практический журнал. - 2018. - Т. 21, № 3.—C. 28-31.

14. Gallant A., Whittier Th., Larsen D. Regionalization as a tool for Managing Environmental Resources // US EPA Environmental Research Laboratory. — 1989. - $182 \mathrm{p}$.

15. Examination of Risk-Based Screening Values and Approaches of Selected States. The Interstate Technology \& Regulatory Council Risk Assessment Resources Team. Washington. - 2005.- $56 \mathrm{p}$.

16. WHO human health risk assessment toolkit: chemical hazards. IPCS harmonization project document.— № 8.— WHO, 2010.— $88 \mathrm{p}$.

17. Carneiro M.F., Moresco M. B., Chagas G. R., Souza 0., Rhoden C. R. et al. Assessment of trace elements in scalp hair of a young urban population in Brazil // Biol. Trace Elem. Res. - 2011. - 143.-P. 815-824.

18. Dongarrà G., Varrica D., Tamburo E., D'Andrea D. Trace elements in scalp hair of children living in differing environmental contexts in Sicily (Italy) // Environ Toxicol. Pharmacol._-2012. - 34 (2). - P. 160-169.

19. Abramczyk H., Brozek-Pluska B., Krzesniak M., Kopec M., Morawiec-Sztandera A. The cellular environment of cancerous human tissue. Interfacial and dangling water as a "hydration fingerprint" // Spectrochim Acta. A Mol Biomol. Spectrosc. - 2014. - Aug 14. 29. - P. 609-623.

20. Water Environment Management in Japan (English version) //Tokyo, Japan: Ministry of the Environment. — 2001.— $46 \mathrm{p}$.

21. Русанова Н. А. Подготовка питьевой воды с учетом микробиологических и паразитологических показателей // Водоснабжение и санитарная техника.1998. - № 4.-C. 13-14.

22. Тунакова Ю.А, Файзуллин Р. И., Валиев В. С., Галимова А. Р. Оценка риска здоровью детского населения при потреблении водопроводной воды с учетом ее вторичного загрязнения // Гигиена и санитария.— 2015.— № 8.—C. 72-76.

23. Джумагалеева Ж. К., Михеева Е. В. Детская заболеваемость в условиях естественной геохимической аномалии // Защита населения и территорий в чрезвычайных ситуациях: сборник трудов II Международной научно-практической конференции. — 2016. — c. 213-217.

(c) Тунакова Юлия Алексеевна ( juliaprof@mail.ru ), Галимова Алина Раисовна ( ARGalimova@kai.ru ), Шагидуллина Раиса Абдулловна ( raisa.shagidullina@tatar.ru ), Валиев Всеволод Сергеевич ( podrost@mail.ru ).

Журнал «Современная наука: актуальные проблемы теории и практики» 